\section{CLINICAL REMARKS} on

\section{SARCINE IN THE URINE FOR FIFTEEN YEARS'. IITHOUT ACCIDENTS.}

BY JAMES FINLAYSON, M.D.,

Physician to the Glasgow Western Infirmary, and to the Royal Hospital for sick Children, Glasgow.

THe chief importance of the first case here given is in indicating the small degree of gravity attaching to the mere discovery of sarcinx in the urine. When one comes across a rarity of this kind, the exact significance or cause of which is not as yet known, there is apt to be considerable anxiety as to what the future developments of the case may be. Although the records hitherto point to the occurrence of sarcinse in the urine as being, in itself, free from danger, any extra security in this sense will be welcomed by those who may have to advise on the matter. The period which has now elapsed since the first detection of the sarcinæ in this case, without urinary accidents supervening, is greater, so far as I know, than any hitherto recorded.

A gentleman, aged about 57, who was well known to me, 'onsulted me' about some trivial ailment, but, in case of there being any latent disease, I thought it well to examine the urine for albumen and sugar, and I found both absent. The specific gravity was 1025. I noticed that the urine was turbid on being passed, and as it was acid in reaction, I was curious to know the rause. Much to my surprise, I found the whitish flocculent-looking sediment which had formed to consist of sarcina I few triple phosphates were also present. The sarcinge were smaller than those with which we are familiar in vomited matter, and they were free from the brown colour so often seen there. This was on Octoher 9th, 1876. On Octoher 13th, the freshly-passed urine was again found to be turbid, with minute shreds visible in the urine rlass; even before it settled, the microscope revealed, in a drop of the urine, the same small sarcinæ as before; the minute shreds were found to consist of white cells and epithelium; the specific gravity was 1025 ; the reaction was acid as before. A fortnight later, this same specimen was found to contain sarcinæ, although the urine had become, of course, quite alkaline; triple phosphates were abundant. Specimens were shown as curiosities at a conversazione of the Glasgow Pathological and Clinical Society held about that time.

Curious to trace the history of the ease, without alarming the gentleman, I took a casual opportunity of examining the urine in February, 1877 ; it was slightly turbid when passed, and sarcine were at once found without even waiting for a sediment to form. The reaction was again acid; and, as before, no albumen could be detected.

No opportunity occurred for ascertaining the continuance of the sarcinæ till I had a chance in March, 1891. The gentleman was then about 71 or 72 years old, but still very active. The urine was turbid, as before, on being passed in the afternoon. It was not examined till next morning, when a loose whitish sediment was seen; the reaction then was alkaline, and numerous triple phosphates were seen; enormous numbers of sarcince were found, small and pale as before; many were in simple groups of four. but some aggregations of many such groups were likewise sem. There were no pus cells visible, and no albumen or sugar could be detected in the urine.

A sample of this was given to Dr. R. M. Buchanan, at the Pathological Laboratory of the Western Infirmary, and he tried cultivations in various media, but failed to obtain any results. He measured the size of the growths, and made them to be 1 micro-millimetre or a little more.

On special inquiry as to any urinary symptoms, it seems that as a boy the patient had retained urine too long on one occasion, and he seems to have had some swelling at the external organs at that time. About 1851, he was troubled with some urinary irritation, with frequent micturition. Dr. S.
Clark, in Glasgow, passed a catheter once at that time, the use of which was followed by the appearance of a little blood. Shortly afterwards he went to consult Professor Syme, in Edinburgh, who sounded him for stone, but none was found. These were the only occasions when instruments were passed into the bladder. The irritability of bladder continued for a year or two, but then ceased to be seriously troublesome, and there was absolutely no pain; a certain nervous anxiety about passing urine continued ever since, showing itself especially if he were in such a position, in a church or otherwise, where exit was difficult. With care in securing an easy retreat, the necessity seldom arose. He had usually to get up to micturate about 4 A.M.; during the day he might pass water every two hours or so. No blood had ever been passed, so far as known, except on the occasion of the catheter being used. His general health had been excellent all his life.

His report in March, 1891, when over 71 years old, was that his health was good, and that he was fit for much active exertion. The urinary symptoms, instead of getting worse with advancing years, had improved, and he could now sit through long services in the church without anxiety as to his bladder.

The only other case of sarcinæ in the urine which I have recognised in my private or hospital practice occurred lately. A married lady was found to have a small quantity of pus in her urine habitually; occasionally the urine became clear, but with an aggravation of her symptoms; there was some tenderness in the left loin, without tumour; all this suggested the presence of a slight pyelitis. I saw her first in September, 1890 , and on examining the urinary sediment was surprised to find with the pus numerous sarcinæ in one or two specimens kept for me. They had not been detected before, although the urine had been repeatedly examined. Mixed up as they were with pus corpuscles, they had evidently been missed. When seen again, in March, 1891, the sarcince were still present, mixed with the pus as before. $A$ s in the other (ase, the size was small and the colour pale. cipecimens given to Dr. R. M. Buchanan for cultivation experiments again failed to show any results.

The history in this case was that about three years ago, when 26 years old, she had her first baby, and about the first week afterwards suffered from retention of urine, with overdistension of the bladder, requiring the use of the catheter for a week. She had a rigor about the fourteenth day, and had then pain on micturition, and a pelvic abscess was feared. Pus appeared in the urine at that time, and has been present ever since, usually in very small quantity. The course of the symptoms made it almost certain that pyelitis and not pelvic abscess was the cause of the rigor. Throughout the case no hlood has been seen, and no albumen could be recognised on testing. The urine is often acid, sometimes neutral ; oxalates have been frequently seen.

Since her illness she has had a second baby without either aggravation or amelioration of her symptoms, which con ist of pain in the back and a sense of exhaustion, varied occasionally by the occurrence of a febrile attack, with more severe pain. When seen by me in March, 1891, she was supposed to be again pregnant. Her appearance did not suggest any grave disease, and she was able to perform her household duties.

In this case the gravity of the condition clearly turns on the pus and on the pyelitis, and not on the sarcinæ.

In both cases, the fact of instruments having been passed into the bladder at one time is very suggestive of contamination from this cause, particularly in view of the considerable proportion of recorded cases of urinary sarcinæ having a similar history of catheterisation.

1 Falkenheim: "Ueber Sarcine," Archiv f. experimentelle Pathol., Bd. 19, Leipzig, 1885.

Dr. RoBert T. Herron has been elected, by a large majority, medical officer of Armagh Workhouse, and consulting sanitary officer in the room of the late Dr. Henry Frazer.

M. JULes JANET has been commissioned by the French Government to study the organisation and practical working of the clinics of urinary diseases in Austria and Switzerland.

Professor E. LuDwig has been elected Dean of the Medical Faculty of the University of Vienna for the academical year 1891-92. 